\title{
The epidemiology of acne vulgaris in late adolescence
}

This article was published in the following Dove Press journal:

Adolescent Health, Medicine and Therapeutics

19 January 2016

Number of times this article has been viewed

\author{
Darren D Lynn' \\ Tamara Umari' \\ Cory A Dunnick ${ }^{2,3}$ \\ Robert P Dellavalle ${ }^{2-4}$ \\ 'Department of Dermatology, \\ University of Colorado School \\ of Medicine, ${ }^{2}$ Department of \\ Dermatology, University of \\ Colorado Anschutz Medical Campus, \\ Aurora, ${ }^{3}$ Dermatology Service, US \\ Department of Veterans Affairs, \\ Eastern Colorado Health Care \\ System, Denver, ${ }^{4}$ Department of \\ Epidemiology, Colorado School of \\ Public Health, University of Colorado \\ Anschutz Medical Campus, Aurora, \\ CO, USA
}

Importance: Acne vulgaris is the most common skin condition affecting late adolescents across the globe. Although prior studies have evaluated epidemiologic patterns of acne vulgaris in various ethnicities and regions, adequate understanding of the worldwide burden of the disease associated with patients in their late adolescence (15-19-year olds) remains lacking.

Objective: To assess the global burden of the disease associated with acne vulgaris for late adolescents (15-19-year olds) and provide an overview of the epidemiology, pathophysiology, and treatment options for acne in this population.

Design: Database summary study.

Setting: Global Burden of Disease Study 2010 database.

Participants: Global Burden of Disease regions comprised countries with prevalence of acne vulgaris between the ages of 15 and 19 years.

Main outcomes and measures: Geographic region-level disability-adjusted life year rates (per 100,000 persons) associated with acne vulgaris in years 1990 through 2010. Median percentage change in disability-adjusted life year rates was estimated for each region across the specified study period.

Conclusion and relevance: Acne vulgaris-associated disease burden exhibits global distribution and has continued to grow in prevalence over time within this population. This continued growth suggests an unmet dermatologic need worldwide for this disorder and potential opportunities for improved access and delivery of dermatologic care. Our analysis of the literature reveals numerous opportunities for enhanced patient care. To that end, we highlight some of the effective and promising treatments currently available and address important factors, such as sex, nationality, genetics, pathophysiology, and diet, as they relate to acne vulgaris in late adolescence.

Keywords: review, epidemiology, GBD, hormones, diet

\section{Introduction}

According to the Global Burden of Disease (GBD) study, acne vulgaris affects $\sim 85 \%$ of young adults aged 12-25 years. ${ }^{1}$ Acne consistently represents the top three most prevalent skin conditions in the general population, as found in large studies within the UK, France, and the USA. ${ }^{2-4}$ Similar numbers are reported for young adults in various countries throughout the world. ${ }^{5}$ The production of androgens during puberty explains, in part, why acne vulgaris is so prevalent in this population regardless of socioeconomic status, nationality, or sex. As of now, the rising incidence of acne vulgaris in late adolescence is a global issue; however, it is unknown whether this increase is a result of higher prevalence of the Western diet, earlier onset of puberty, genetic drift, or a byproduct of unknown environmental factors.
Correspondence: Robert P Dellavalle Dermatology Service, US Department of Veteran Affairs Medical Center, 1055 Clermont Street, Box 165, Denver, CO 80220, USA

Tel +l 3033998020 ext 2475

Fax +I 3033934686

Email robert.dellavalle@ucdenver.edu 
Despite its prevalence, misconceptions of the initiating and exacerbating factors that influence the development of acne vulgaris continue to exist. By providing data that accurately describe the epidemiology, risk factors, pathogenesis, genetics, comorbidities, and treatment associated with acne vulgaris in late adolescence, we hope to improve the awareness of the demographics affected by this condition and lead to important changes in patient education and treatment. Additionally, it is useful for physicians to be aware of these important issues associated with acne vulgaris to fully and successfully treat patients.

\section{Search methods}

The PubMed database was searched for articles published from 1975 to May 2015 using the term "acne vulgaris" in combination with epidemiology, adolescent, puberty, genetics, race, nationality, socioeconomic status, diet, Western diet, dairy, whey protein, chocolate, glycemic index, drugs, smoking, nicotine, oral contraceptives, and treatment. All review articles published within the last decade that included the previously mentioned terms were examined in addition to the articles which they cited that contained one or more of the previous key search terms in their title. Articles that focused on a population outside of the adolescent to young adult period were excluded in this study. Analysis of burden of the disease of acne vulgaris was done using the data from the GBD Compare search software. ${ }^{1}$ The goal of this study was to create a review about acne vulgaris as it relates to patients in their late adolescence, $15-19$-year olds.

\section{Epidemiology Nationality and acne vulgaris}

Globally, epidemiological studies have demonstrated a higher incidence of acne vulgaris in different ethnicities of color in samples collected from the population aged 10-70 years. ${ }^{6,7}$ However, contradictory evidence exists as to whether a biological difference actually exists among various racial or ethnic groups in the pathogenesis of acne. ${ }^{89}$ Moreover, there are no reported studies that delineate the incidences of acne vulgaris among these different ethnicities in patients who are in their late adolescence. To address this, we analyzed the collection of data gathered from the 2010 GBD Compare study over specific regions, controlling for specific age ranges (in this case, 15-19-year olds) to see the trend in disabilityadjusted life year (DALY) rates per 100,000 people. The DALY rate is equal to the years of life lost plus the years living with the disability (YLDs). Since the years of life lost for acne vulgaris is zero, the rate of DALYs is equal to the rate of YLDs. Calculation of YLDs is defined as the prevalence of the disease multiplied by the relevant disability weight. By dividing the rate of DALYs of 15-19-year olds by the rate of DALYs of all ages within the given population, we are left with a surrogate measure of the comparative rate of incidences of acne vulgaris in people aged 15-19 years per 100,000 people in any region listed between 1990 and 2010. The results are shown in Figure 1A and B.

Figure 1A exhibits a general upward trajectory for all regions except Sub-Saharan Africa, with a clear separation in both prevalence and rate of incline between traditionally more wealthy regions (Western Europe, high-income Asia Pacific, US, and Canada) and traditionally poorer regions (Sub-Saharan Africa, Oceania, Latin America, and Caribbean). Similar patterns are seen for incidence and rate of incline in the comparison of developing versus developed nations, as shown in Figure 1B. While it is possible to infer that the variances observed in these ethnically distinct regions are due to racial differences, this theory is confounded by the fact that many of these regions are racially diverse and heterogeneous in population.

These data are limited by the consistency of physicians reporting clinically significant acne. The data provided by the GBD database do not specify the body location associated with the reported acne vulgaris. The degree of severity shared across populations is assumed to be similar to other studies, such as the one by Bagatin et al, ${ }^{10}$ where 452 adolescents aged between 10 and 17 years (mean $=13.3$ years) showed comedonal as the most prevalent form of acne $(61.1 \%$ - CI $95 \%[56.5 \% ; 65.7 \%])$, followed by mild $(30.6 \%$ - CI $95 \%$ $[26.3 \% ; 34.9 \%])$ and moderate papular-pustular $(7.6 \%-\mathrm{CI}$ $95 \%[5.1 \% ; 10.1 \%])$.

In addition, the data in Figure 1A or B should not be confused with the prevalence of acne vulgaris within a given population. The raw prevalence of acne vulgaris for patients aged 15-19 years for each region listed in 2013 can be found through the University of Washington tool http://vizhub.healthdata.org/gbd-compare/. Interestingly, Taiwan (of East Asia), Western Europe, and South Asia have the highest prevalence in the 15-19 age group among their respective unadjusted age population despite their difference in the rate of incidence. Taken together, these data demonstrate that the causes and treatment of acne vulgaris in late adolescence are likely complex and multifactorial in nature, reflecting the interplay of many factors such as increased access to proper health care, socioeconomic status of individuals and families, and shifting cultural perceptions of skin care and beauty. 
A

Acne vulgaris
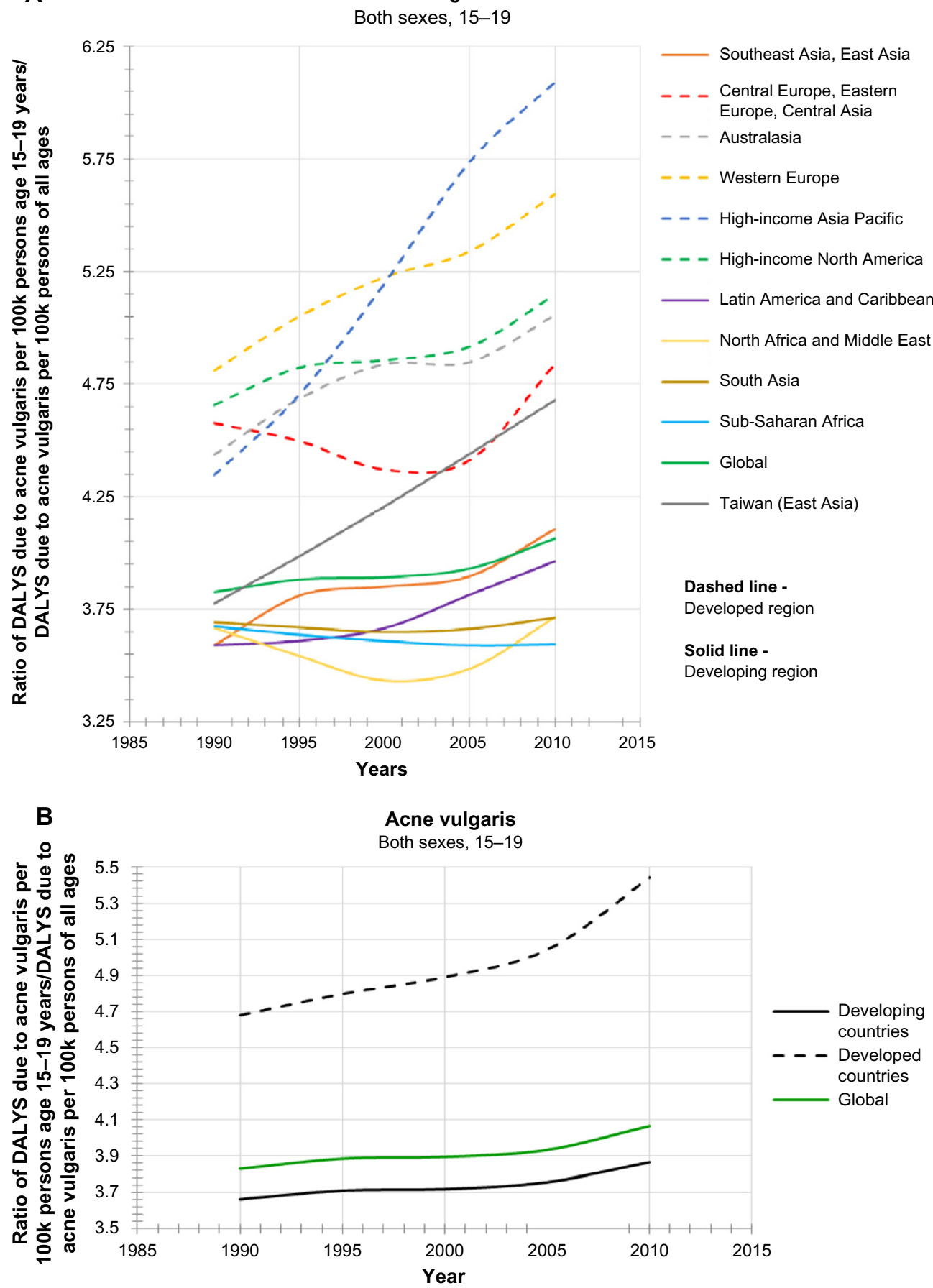

Figure I Acne vulgaris in late adolescence around the globe.

Notes: (A) The proportional rate of DALYs of 15-19-year olds in a given region for acne vulgaris. (B) This figure demonstrates a similar finding when comparing developing and developed countries.

Abbreviation: DALY, disability-adjusted life year.

There is an abundance of epidemiological research done in the US and other "first world" countries documenting an increased prevalence of patients with skin of color being seen for acne vulgaris. ${ }^{11}$ While the pathogenesis of acne has not been shown to differ biologically between those with light skin versus dark skin, the difference in postinflammatory hyperpigmentation has been well established and is often the main concern regarding acne in patients with skin of color. ${ }^{12,13}$ Coupled with an enhanced access to health care, it is no wonder why the US and other first world regions would report higher incidences of acne in dark-skinned individuals. At least in the US, as the Affordable Care Act continues 
to enhance the health care access in our society and as the projected US population continues to shift, these reported incidences within different ethnic groups will undoubtedly continue to increase.

As noted, cultural perceptions or attitudes toward acne is also reflected in our analysis. For example, it has been noted that the South Asian population, in general, tend to believe that diet and poor hygiene play a significant role in the pathogenesis of acne and tend to self-treat by excessive scrubbing or face washing. ${ }^{6}$ This common perception was addressed in 2005 by a comprehensive systematic review of eleven studies which concluded that there was insufficient evidence to link facial cleansing or hygiene maintenance to causing, exacerbating, or curing acne vulgaris in patients. ${ }^{14-16}$ The incidence of acne vulgaris in this population is complicated by poor access to health care and a cultural belief in holistic and complementary medicine. ${ }^{6}$ Taken as a whole, this population is less likely to take oral medications or consult a licensed dermatologist or physician.

Cultural differences regarding skin and hair care practices have also been cited as possible factors contributing to the variable incidence of acne vulgaris among different ethnic populations. Within the black population, for example, a common practice is frequent use of lotions containing cocoa butter, a highly comedogenic substance, with the intent to get even skin tone and improve hyperpigmented scars. ${ }^{13}$ Other reports have described patients of African descent using certain pomades (a mixture of petrolatum, lanolin, and oils) as a moisturizer for their hair and scalp, with acne erupting secondary to long-term use. ${ }^{17}$

\section{Pathophysiology}

Acne vulgaris is a disease affecting the pilosebaceous unit (PSU) of the skin and is typically described as either noninflammatory (open and closed comedones) or inflammatory (papules and pustules). ${ }^{5}$ The basement membrane of PSU, the same epidermal-dermal barrier seen in the skin, surrounds the PSU and provides structural support for its basic components including the hair, hair follicle, erector pili muscles, and sebaceous gland. The basement membrane is lined with basal stem cells that, given the correct hormones from the body, develop into sebaceous cells and keratinocytes that produce oil and hair, respectively. Lining the central canal of the follicular part of the PSU are squamous epithelial cells, also known as ductal lining cells. When stimulated by hormones, namely androgens, these cells (the sebaceous cells, keratinocytes, and ductal lining cells) are activated and begin to proliferate. When the proliferating ductal lining cells cannot escape the infundibulum of the PSU, they form a plug, backing up the sebum production and hair growth that continue beneath it. The pressure within the unit compromises the availability of diffusible oxygen to cells below, constraining their metabolism and providing an ideal, anoxic environment for flora (Proprionibacterium acnes) to grow. Moreover, the overproduction of sebum provides a resource of nutrients in the form of fatty acids to bacteria rapidly multiplying within the PSU.

Once growth beneath the plugged PSU surpasses the retention capacity of its structural basement membrane, it bursts and exposes its contents to our body's immune system. P. acnes is an anaerobic, Gram-positive rod present in a natural part of our skin's flora as well as the main instigator linked to the inflammation of acne. Malassezia furfur is a yeast that is also naturally found on the skin surface and can contribute to the pathogenesis of acne. White blood cells immediately recognize the lipoproteins of this foreign pathogen through receptors, specifically the Toll-like receptor- 2 and Toll-like receptor-4, stimulating keratinocytes to secrete interleukin-6 and interleukin-8 and giving rise to erythematous inflammation. ${ }^{18,19}$ Eventually, inflammatory mediators recruit white blood cells to mount an attack against the pathogens, resulting in the formation of an erythematous pustule. Over time, the inflammatory response repairs the damage within the PSU and the skin returns to normal.

\section{Hormones}

Dihydrotestosterone (DHT), an endogenous androgen, is one of the potent acnenogens derived from a number of readily available precursors found in both men and women. Its formation is brought about by the direct action of enzymes found within the PSU (Figure 2). ${ }^{20}$ Prior to puberty, during adrenarche, the adrenal cortex secretes the androgens dehydroepiandrosterone and its longer lasting sulfate, dehydroepiandrosterone sulfate. ${ }^{21}$ Adrenarche continues until high levels of gonadotropin-releasing hormone pulses cause the onset of puberty, which begin on average between ages 10 and 11 years for females and 11 and 12 years for males. ${ }^{22}$ Throughout puberty, the native enzymes of PSU can convert testosterone precursors produced by male testes, female ovaries, and adrenal glands (in both sexes) to DHT via a stepwise reaction. ${ }^{23}$ Once converted, DHT has the capability of binding to and activating its intranuclear receptor; however, this receptor is regulated by the transcription factor, Forkhead box protein $\mathrm{O} 1$ (FoxO1). ${ }^{24}$ The regulatory capacity of FoxO1 is inhibited by the protein kinase Akt, a downstream target associated with insulin- and insulin-like growth factor 1 


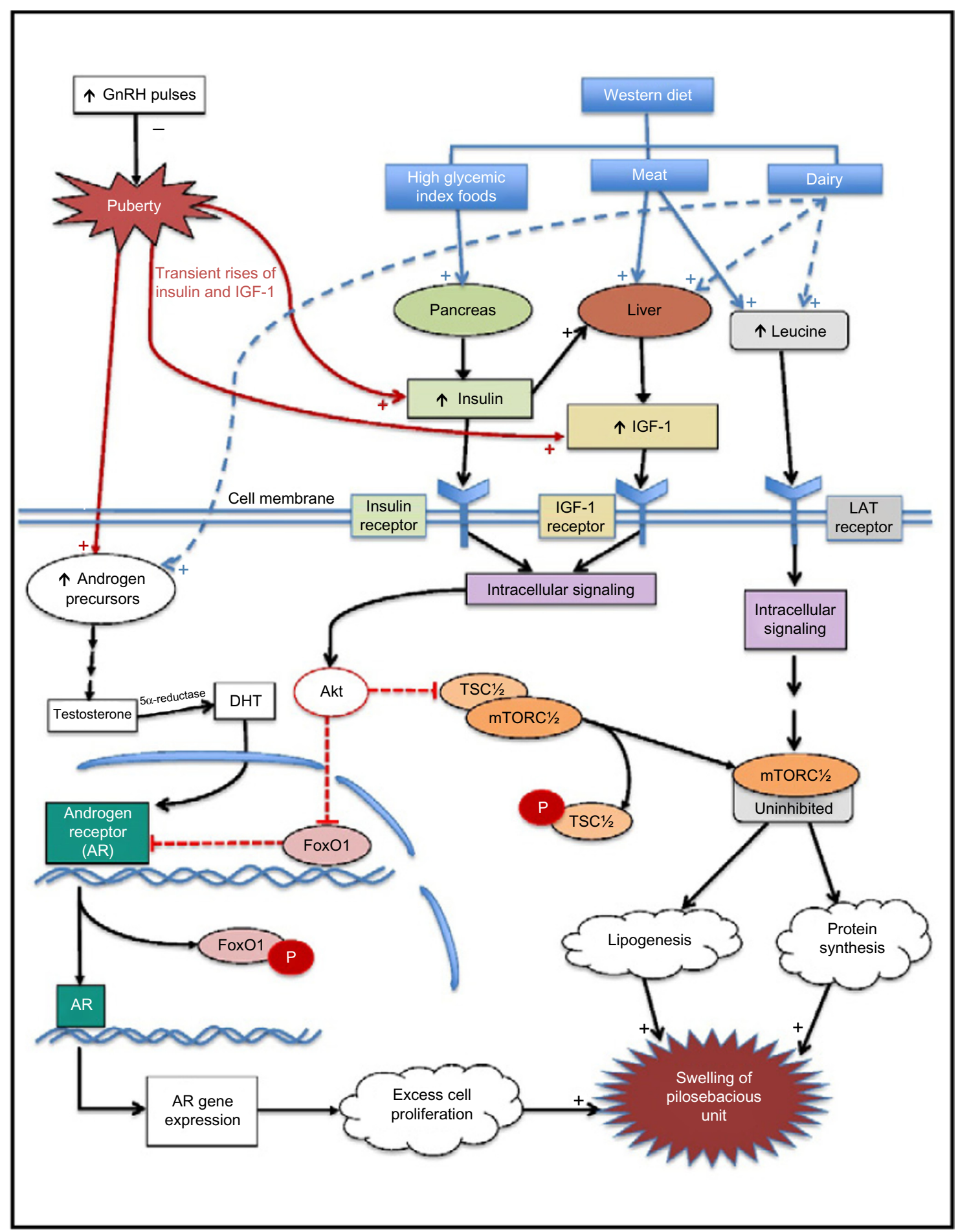

Figure 2 Cellular mechanisms hypothesized to govern the pathogenesis of acne vulgaris.

Abbreviations: GnRH, gonadotropin-releasing hormone; IGF, insulin growth factor; DHT, dihydrotestosterone; FoxOI, Forkhead box protein OI; mTORC, mammalian target of rapamycin.

(IGF-1)-receptor activation. ${ }^{25}$ Transient rises of insulin and IGF-1 occurring during the normal course of puberty inhibit FoxO1 regulation and allow the activated androgen receptor to trigger a chain of metabolic events, which lead to an excess production of keratinocytes and sebum. ${ }^{26}$ This process is augmented by the additional regulatory duty of Akt on TSC1/2, an inhibitor of mTOR, where its inactivation allows mammalian perform its downstream signaling duties, which will inevitably lead to the increase of lipid and protein synthesis within the PSU (Figure 2). ${ }^{24,27}$ 
While the occurrence of acne vulgaris in males and females is initiated by the onset of puberty, it is most likely prolonged into late adolescence by transient increases in insulin and IGF-1 levels. This trend is readily seen when using the rate of DALYs for acne vulgaris provided by GBD Compare, where a quantitative difference between the onsets of male versus female puberty can be seen on a global level in 2010, with females reporting a higher incidence of the disease at younger ages (Figure 3). For reasons explained previously, we see a separation in the rate of incidences between developed versus developing countries. Interestingly, the rate of acne vulgaris among females remains higher than their male counterparts. As the incidence of acne vulgaris peaks at the age 15 for both sexes, we begin to see a decline in late adolescence consistent with average age of puberty completion (15-17 years for females and 16-17 years for males).$^{28}$ It should be noted that acne prevalence continues to persist until the third decade of life, due to a slower decline of insulin and IGF-1 levels peaking during late puberty and gradually declining. ${ }^{26,29,30}$ Moreover, there is thought to be a greater severity of acne in males than in females during the late adolescent period, which is not depicted in the graph. ${ }^{31}$

Throughout all ages, there is a higher proportion of reported incidences of acne vulgaris in females than in males - regardless of a country's economic status. The factors attributing to the incidence difference seen between males and females are, once again, likely complex and multifactorial. Indeed, whether the variance of incidence among men versus women in this age group is due to greater attention to skin care, the use of certain cosmetics, or exogenous hormone sources, including diet, requires further research.

\section{Diet}

The "Western diet" is a dietary regimen characterized by high amounts of sugary desserts, refined grains, high protein,
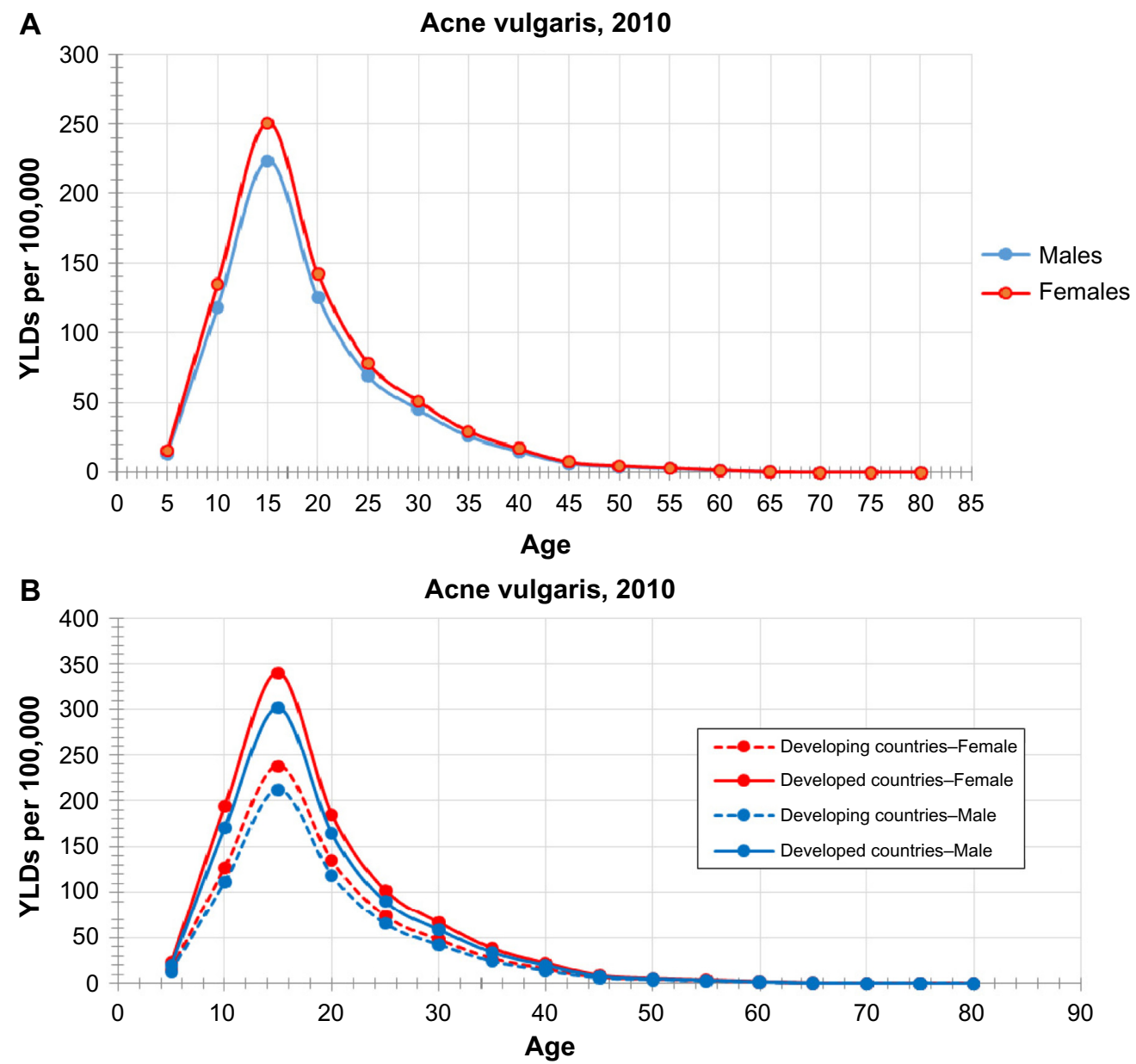

Figure 3 An earlier puberty onset for females triggers a higher incidence of acne vulgaris in the younger age ranges compared to men, regardless of a country's economic level. Note: Change in the rates of incidence across all age categories compared between 1990, 1995, 2000, and 2005 were negligible and, therefore, not included in the data set.

Abbreviation: YLD, years living with the disability. 
high-fat dairy products, and high-sugar drinks and is commonly seen in some developed countries with increasing frequencies, and this trend is now evident in developing countries also. As patients in the late adolescence become more independent, their freedom to choose what and where to eat can often lead to these "Westernized" diets; in the US, $>80 \%$ of fast-food restaurant visitors are individuals younger than 18 years. ${ }^{32}$ As these types of foods become cheaper and more ubiquitous, it comes as no surprise that nations outside the US are starting to see a similar trend of rising rates of obesity, insulin resistance, and acne among the younger populations. ${ }^{33-35}$ Conversely, there are also populations documented that abstain from a Western diet, eating meals low in meat and devoid of grains or dairy products. As a result, acne vulgaris is absent in these populations. ${ }^{36}$

\section{High glycemic index foods}

The glycemic index is simply a number assigned to any effect of a particular food on an individual's blood glucose level, typically ranging between 50 and 100. ${ }^{37,38}$ High glycemic index foods $(>70)$, including glucose, white bread, white rice, and chocolate, stimulate the release of insulin from beta cells of the pancreas.

Insulin activates the Akt signaling pathway directly through its receptor and indirectly through the production of IGF-1 and its receptor. ${ }^{25,37}$ The effect of IGF-1 on the cells of the PSU is two-pronged: either stimulating enzymes taking part in stepwise DHT synthesis pathway or directly activating its receptor (IGF-1R) on the cells. ${ }^{25}$ The latter pathway will converge with the downstream signaling events of the insulin receptor, binding to and activating the protein kinase Akt. ${ }^{25}$ Akt can then phosphorylate its target in the nucleus, FoxO1, and inactivate it. ${ }^{25}$ FoxO1 deactivation leaves the androgen receptor, a highly active and vulnerable target during late adolescence, free to induce the necessary gene transcription that drives the proliferation of keratinocytes (Figure 2).

Some evidence to support this concept comes from a randomized, controlled trial in which recruited male participants, aged 15-25 years, with mild-to-moderate facial acne were separated and instructed to eat a diet of high protein low glycemic index foods or the conventional high glycemic load diet. ${ }^{38}$ After 12 weeks, total lesion counts had decreased more in the low glycemic index diet group than in the control; moreover, this experimental group demonstrated lower free androgen index and insulin levels than the control. Other randomized controlled trials have since been released, similarly demonstrating the definitive effect of high glycemic index foods on acne in young adults across different ethnicities. ${ }^{34,35}$

\section{Dairy}

Unlike high glycemic index foods, there have been no randomized controlled trials to date that have investigated a relationship between dairy consumption and acne. ${ }^{39}$ Nevertheless, there are numerous research studies that suggest a correlational relationship, some dating as far back as $1925 .^{40}$ In the US, Adebamowo et $\mathrm{al}^{41-43}$ were the first to report retrospective and prospective epidemiological studies directly linking clinical acne and milk or dairy consumption with participants in their late adolescence. At a cellular level, high amounts of dairy are thought to promote acne pathogenesis by providing exogenous hormones and by stimulating pathways that converge with the effects of insulin on the PSU. ${ }^{25,37}$ To our knowledge, there have not been any studies that indicate a higher rate of dairy consumption among the late adolescent period; yet, with the popularity of breakfast cereals, ice cream, cheese, butter, chocolate milk, and powdered whey proteins among this population, it is easy to speculate how such an association could be made.

Amino acids, primarily leucine, found in dairy milk and whey directly stimulate the L-type amino acid transporter (LAT) found in sebaceous cells and keratinocytes, signaling a cascade of downstream signaling events that lead to activation of mTORC1, independent of the Akt signaling pathway (Figure 2). ${ }^{38}$ This protein is thought to control the lipogenesis and protein synthesis that drive sebaceous activity and ductal plugging, respectively. ${ }^{37}$

Apart from amino acids, (cow) milk is also known to contain exogenous steroid hormones that are true anabolic androgen precursors of DHT, including 5a-pregnanedoine, 5a-pregnan-3B-ol-20-one, 5a-androstene-3B, 17B-diol, 5a-androstanedoin, and 5a-androstan-3B-ol-17-one. ${ }^{44,45}$ At this time, it is unknown whether these particular molecules share activating capabilities similar to DHT; however, their presence increases the amount of substrate available for 5a-reductase that, in turn, can produce more DHT. ${ }^{20}$

\section{Meats}

Meat, a staple food of the Western diet, is one of the most popular menu items consumed by patients in late adolescence or young adulthood in Western countries. Muscle and egg protein are high in leucine content ( $8 \%$ and $8.5 \%$, respectively) and, therefore, can work in a similar pathway as dairy goods. ${ }^{46}$ However, there is a wealth of literature that attests to the ability 
of amino acids (the fundamental component of protein) in inducing the secretion of IGF-1 from the liver. It is this latter mechanism that has been hypothesized to be at work in the pathogenesis of acne; however, the evidence to support this as a significant contribution to acnegenesis is limited.

\section{Smoking and nicotine}

Globally, the ingestion of nicotine from tobacco products is highest among young adults (18-25-year olds), although the rate of usage has been declining in developed regions, developing regions have seen an incline, particularly in young adult men. ${ }^{47,48}$ In recent years, the popularity of electronic cigarettes has given nicotine consumption a boost, particularly among the late adolescents in the US. ${ }^{49,50}$ Epidemiologic studies suggest a dose-dependent correlation between smoking and acne, in both prevalence and severity, citing nicotine as a possible inciting factor behind the pathophysiologic process; however, the biological evidence supporting this process is limited and controversial. ${ }^{51-53}$ One theory proposes that the excess nicotine acts on the nicotinic receptors expressed on keratinocytes, fibroblasts, and blood vessels found in the PSU, inducing vasoconstriction with local hyperemia. ${ }^{53}$ The vasoconstriction is thought to delay wound healing by inhibiting the inflammatory effect necessary to dispose the rapidly growing bacteria and to fix the ruptured PSU. ${ }^{53}$ Another theory, while less understood, suggests that smoking causes a relative deficiency in antioxidants within the patient, leading to modifications in sebum composition, which adds to the relative severity and presentation of acne vulgaris. ${ }^{54}$

\section{Comorbidities}

Acne vulgaris in late adolescence is associated with numerous psychological comorbidities, with female patients being more prone to emotional and behavioral difficulties than their male counterparts. ${ }^{5,55-57}$ Many of these studies cite low attachment to friends, not thriving at school, lack of romantic relationships, and lack of relational intimacy as predominant findings. Other studies have found additional evidence of psychosocial impairment, showing associations between acne and other comorbidities, such as attention deficit disorder and attention deficit hyperactivity disorder $(P=0.01)$, insomnia $(P=0.02)$, poor body image, and body dysmorphic disorder. ${ }^{56,58}$ In addition to these psychosocial behaviors secondary to acne vulgaris, various studies have also highlighted association of acne with anxiety, diminished self-esteem, social isolation, depression, and suicide. ${ }^{56,57}$ Of the reported psychological effects, suicidality is an important comorbidity, particularly in more moderate-to-severe cases. ${ }^{5}$ One study revealed a strict correlational relationship to suicidal ideation when comparing those with significant acne ("a lot and very much") to those with more mild acne ("no/little acne"). Girls with significant acne displayed suicidal ideation "twice as frequently" as their counterparts in the mild acne group (25.5\% vs $11.9 \%$ ). Similarly, boys with significant acne reported suicidal ideation three times more frequently than those with mild acne $(22.6 \%$ vs $6.3 \%) .{ }^{55}$ Unfortunately, the psychogenic changes associated with these acne sufferers often exacerbate the condition, perhaps further worsening their mental health. One study in People's Republic of China analyzed the psychological well-being of those suffering from severe acne and found that their cumulative negative life events, in fact, accelerated both the occurrence and the exacerbation of the condition. ${ }^{59}$

While the large majority of acne comorbidities revolve around mental health, acne in late adolescence is also associated with other diseases. ${ }^{60}$ Of these, sinus infection and asthma were seen widely in patients with severe acne who were also using prescription medication. ${ }^{61,62}$ Moreover, those patients concomitantly taking medication were also seen to have a higher percent of gastrointestinal problems, including nausea, vomiting, and abdominal pain. ${ }^{60}$ While other studies have implicated the possible association of antibiotics in acne, its modification of resident flora, and the possible association of drug-resistant acne, no conclusive clinical data and connection have been established. ${ }^{61,63}$ The distinguishing role of acne, if any, and its relevant pathogenesis that may take part in the production of these symptoms has yet to be elucidated.

\section{Genetics}

The genetic component of acne vulgaris has been described in twin studies, with some studies citing late adolescent acne patients having at least one first-degree relative with this condition. ${ }^{64,65}$ Human leukocyte antigen genes, cytochrome p450 genes, and even certain glycoproteins have been implicated in the genetic predisposition to acne vulgaris. ${ }^{66-68}$ Due to the complexity of the pathogenesis of acne, there are likely many heritable factors contributing to the development of acne, and a summary of the cellular events described in this paper is shown in Figure 2.

The multifactorial nature behind the driving force of acne makes mutations conferring over- or underactivation in any one of the enzymes and receptors described in this review or illustrated in Figure 2 as possible genetic influences to acne pathogenesis. For example, Laron syndrome, a rare recessive disease in which there is inadequate production of 
IGF-1, is one of the few known phenotypes in which patients documented that they have never suffered from any degree of acne vulgaris. ${ }^{69}$ Conversely, overactivation of IGF-1, commonly seen in insulin-resistant and obese patients, has been associated with excess androgen production and a higher degree of morbidity from acne vulgaris. ${ }^{70,71}$ Patients in their late adolescence are particularly susceptible to changes affecting the ability of FoxO1 to regulate androgen receptor activity, given the high concentration of androgen hormones produced by puberty. Moreover, it has been documented that transient rises of insulin secretion arising from insulin resistance occur during both normal puberty and adolescence - further adding to the molecular complexities that drive acne pathogenesis. ${ }^{26,29}$ Indeed, one of the most successful acne treatments available for patients in their late adolescence, isotretinoin, has been heavily implicated in the suppression of sebum production and IGF-1 serum levels via the upregulation of FoxO1. ${ }^{27}$

\section{Treatment}

The treatment of acne vulgaris in late adolescence is approached in much the same way as in the rest of the population. Treatment options for acne vulgaris have been well described in the literature, and as a result, this list is not meant to be exhaustive. We aim to provide the reader with generalized treatment options currently being used and those in development for acne vulgaris in late adolescence.

\section{Topical}

Benzoyl peroxide is a mainstay in over-the-counter treatment of acne vulgaris. It is safe and works by reducing $P$. acnes colonization without risk of resistance, and low concentrations $(2.5 \%-5 \%)$ can be used with minimal irritation. ${ }^{72,73}$ As a stand-alone agent, benzoyl peroxide is as efficacious as oral antibiotics and is superior to topical tretinoin for inflammatory lesions. ${ }^{72}$

Topical retinoids remain a fundamental treatment option for clinical acne and continue to be a first-line option for mild-to-moderate acne vulgaris. ${ }^{72,74}$ Topical retinoids expel mature comedones, decrease microcomedone formation, and possess anti-inflammatory properties due to molecular interactions involving Toll-like receptors, nitric oxide, and cytokines. ${ }^{72}$ While contraindicated in pregnancy, topical retinoids still possess a relatively favorable safety profile and exhibit primary side effects of local irritation, erythema, and dryness. ${ }^{72}$

While by no means new, azelaic acid is another treatment option that has been proven to be as effective against both noninflammatory and inflammatory lesions in topical monotherapy as benzoyl peroxide (5\%) and clindamycin (1\%). ${ }^{74,75}$ A new nonalcoholic hydrogel containing $15 \%$ azelaic has been developed and is thought to work by reducing $P$. acnes proliferation and normalizing keratin production. ${ }^{75}$ Azelaic acid gel might be a viable option for patients suffering from mild-to-moderate acne vulgaris resistant to other topical therapeutics for whom the use of systemic or hormonal treatments is contraindicated.

\section{Antibiotics}

Topically, the macrolides, clindamycin, and erythromycin are used for their bacteriostatic effect on $P$. acnes as well as their anti-inflammatory properties and are typically used for mild-to-moderate acne. ${ }^{76,77}$ Systemic or oral antibiotic therapy in the form of minocycline, doxycycline, or tetracycline, however, is typically indicated when moderateto-severe inflammatory acne is present. ${ }^{78}$ Reviews on the comparative clinical effectiveness of these systemic antibiotic treatments have failed to reveal any as superior to the others in the treatment of acne. ${ }^{79}$ Administration of tetracyclines should be avoided among pregnant women as they are associated with brown tooth discoloration; therefore, women of childbearing age should concomitantly take contraceptive measures. Erythromycin may be used in patients allergic to tetracyclines, but little evidence exists to support the use of other oral antibiotics (ie, clindamycin, cotrimoxazole, quinolones). The concomitant use of systemic and topical antibiotics should be avoided when possible. ${ }^{72,80}$

One of the biggest concerns surrounding the treatment of acne vulgaris with antibiotics (either topical or systemic) is increasing $P$. acnes resistance, especially in monotherapy. ${ }^{81}$ To avoid resistance, antibiotics should be limited to a 12 -week course and used alongside either retinoids or benzoyl peroxide. $^{76,80}$

\section{Systemic}

Oral isotretinoin therapy is one of the most efficacious therapies for the treatment of severe acne since its introduction in $1982 .{ }^{82}$ It works by targeting all components associated with the pathogenesis of acne, upregulating FoxO1, decreasing sebum production, decreasing bacterial growth, and even demonstrating anti-inflammatory effects. ${ }^{27,83}$ The usual course of isotretinoin lasts 16-24 weeks, with increasing amounts used as tolerated until the target dose, typically between 120 and $150 \mathrm{mg} / \mathrm{kg}$, is reached. ${ }^{76,84}$ Use in late adolescence, however, has an increased risk in relapse, especially in women 
with hormonally driven acne and up to $20 \%$ of all other younger patient populations. ${ }^{85,86,87}$

Use of oral isotretinoin is only available through specialist care in many countries, being tightly regulated as a result of its teratogenic effects. ${ }^{81}$ In addition, oral isotretinoin therapy has been linked with rare cases of depression, suicidality, and inflammatory bowel disease. ${ }^{88}$ Other common side effects seen in low-dose therapy include dry mouth, dry nose, dry skin, dry eyes, myalgias, abnormal wound healing, sunburn susceptibility, desquamation of palms and soles, and overall fragility of skin, most of which resolve after the treatment is stopped. . $^{7,83,89,90}$

\section{Hormonal}

Oral contraception, used properly, can be an effective method in treating acne vulgaris among female patients in their late adolescence. Most birth control, regardless of the route of administration, consists of a combination of estrogen and progestins, which increases the production of a protein called sex hormone-binding globulin in the blood, which binds the free testosterone in the blood capable of activating the androgen receptors in the PSU. ${ }^{91,92}$ Today, drospirenone is considered to be most effective in managing androgen levels in women, but it does come with significant side-effects..$^{93}$ It should be emphasized that the use of any oral contraceptive, not solely drospirenone, is associated with a well-established increase in the frequency of blood clotting. This can lead to lifethreatening conditions, such as the formation of pulmonary embolisms, and the administration of an oral contraceptive as a treatment for acne vulgaris should be approached with caution. ${ }^{94}$ At the time this article was written, the progestin norgestimate has been presented as a reasonable alternative to drospirenone in treating acne vulgaris for those with a higher risk of blood clots, although it is slightly less effective in the management of acne..$^{95,96}$

Androgen blockers that can theoretically be used by both sexes, including spironolactone, cyproterone acetate (Diane-35), finasteride, dutasteride, and flutamide, have not been well studied in patients who are in their late adolescence. ${ }^{97-100}$ However, their speculative ability to block the androgen-mediated activation of the PSU and circumvent acnegenesis has been demonstrated in a number of clinical trials, along with potent side effects. ${ }^{98,100,101}$ Further research is required to determine whether these androgen blockers can be used safely and effectively in male and female patients in their late adolescence.

\section{Conclusion}

Acne vulgaris, according to the GBD, is the tenth highest cause of DALYs in the late adolescent period (15-19-year olds) across developed countries. ${ }^{1}$ It encompasses a multifactorial disease process that can affect individuals regardless of age, sex, or nationality. It is particularly prevalent during the late adolescent period, which many sources regard as being between the ages of 15 and 18 years, most likely initiated by the onset of puberty. The cellular mechanisms at play during this time frame mostly involve an increase in androgens capable of stimulating an intranuclear receptor and activating the proliferation of cells within the PSU. The Western diet, including meats, dairy, and high glycemic index foods, can also influence this same pathway by inactivating the regulator of the androgen receptor, FoxO1. Another environmental factor seen to play a role in acnegenesis is smoking, although evidence is lacking.

The cellular physiology underlying the pathogenesis of acne vulgaris is complex, and any number of dysfunctional or overactivated proteins can affect the genetic component of the disease. The consideration of the effects of acne on patients in their late adolescence should not be confined to the dermatological realm due to the pervasive psychosocial comorbidities among patients plagued with the disease. While girls are often more susceptible than boys, both sexes frequently suffer from anxiety, depression, and suicidality along with their acne vulgaris. Treatments for the disease are typically topical: benzoyl peroxide or retinoids; antibacterial: macrolides (topical) or tetracyclines (oral); hormonal: oral contraceptives or androgen receptor blockers; or systemic: isotretinoin. Each treatment option can be tailored to the patient based on his or her clinical presentation. Sometimes severe side effects do occur, so patient education is important.

In conclusion, there are many contributing factors that uniquely influence the incidence, prevalence, and persistence of acne vulgaris in the late adolescent population. Many of these factors deserve special attention when considering a treatment approach for acne vulgaris in this population. Diet, psychological comorbidities, and hormones may be especially impactful to young adolescents and may, therefore, be particularly amenable to intervention. Continued efforts to identify and better understand the factors specific to patients in the late adolescent period are important. Incorporating a more unified education and treatment regimen for this population may serve as a way to bring the global incline in the incidence of acne vulgaris to a halt.

\section{Acknowledgments}

There was no direct funding to the current study. The Global Burden of Disease study received funding from the Bill and Melinda Gates Foundation (PI: Christopher JL Murray). The US Department of Veterans Affairs had no role in the design and execution of the study. Any opinions expressed herein 
do not necessarily reflect the opinions of the US Department of Veterans Affairs. The Bill and Melinda Gates Foundation and the Department of Veterans Affairs were not involved in the current study design, data acquisition and interpretation, or manuscript preparation or review.

\section{Author contributions}

DDL and RPD had full access to all of the data in the study and take responsibility for the integrity of the data and the accuracy of the data analysis. Study concept and design: RPD and DDL. Analysis, interpretation of data, and drafting of the manuscript: DDL and TU. Critical revision of the manuscript for important intellectual content: RPD, DDL, TU, and CAD. Statistical analysis: DDL. Administrative, technical, or material support: RPD. Study supervision: RPD. All authors contributed toward data analysis, drafting and revising the paper and agree to be accountable for all aspects of the work.

\section{Disclosure}

RPD is an employee of the US Department of Veterans Affairs. RPD is supported by grants from the CDC and National Institutes of Health. The authors report no other conflicts of interest in this work.

\section{References}

1. Seattle WI. GBD Compare. Seattle: University of Washington; 2013.

2. Rea JN, Newhouse ML, Halil T. Skin disease in Lambeth. A community study of prevalence and use of medical care. Br J Prev Soc Med. 1976;30(2):107-114.

3. Wolkenstein P, Grob JJ, Bastuji-Garin S, Ruszczynski S, Roujeau JC, Revuz J. French people and skin diseases: results of a survey using a representative sample. Arch Dermatol. 2003;139(12):1614-1619. [discussion 1619].

4. Johnson MT, Roberts J. Skin conditions and related need for medical care among persons 1-74 years. United States, 1971-1974. Vital Health Stat. 1978;11(212):i-v, 1-72.

5. Bhate K, Williams HC. Epidemiology of acne vulgaris. Br J Dermatol. 2013;168(3):474-485.

6. Quarles FN, Johnson BA, Badreshia S, et al. Acne vulgaris in richly pigmented patients. Dermatol Ther. 2007;20(3):122-127.

7. Davis EC, Callender VD. A review of acne in ethnic skin: pathogenesis, clinical manifestations, and management strategies. J Clin Aesthet Dermatol. 2010;3(4):24-38.

8. Pochi PE, Strauss JS. Sebaceous gland activity in black skin. Dermatol Clin. 1988;6(3):349-351.

9. Grimes P, Edison BL, Green BA, Wildnauer RH. Evaluation of inherent differences between African American and white skin surface properties using subjective and objective measures. Cutis. 2004;73(6):392-396.

10. Bagatin E, Timpano DL, Guadanhim LR, et al. Acne vulgaris: prevalence and clinical forms in adolescents from Sao Paulo, Brazil. An Bras Dermatol. 2014;89(3):428-435.

11. Perkins AC, Cheng CE, Hillebrand GG, Miyamoto K, Kimball AB. Comparison of the epidemiology of acne vulgaris among Caucasian, Asian, Continental Indian and African American women. J Eur Acad Dermatol Venereol. 2011;25(9):1054-1060.

12. Halder RM, Nootheti PK. Ethnic skin disorders overview. J Am Acad Dermatol. 2003;48(6 Suppl):S143-S148.

13. Callender VD. Acne in ethnic skin: special considerations for therapy. Dermatol Ther. 2004;17(2):184-195.
14. Friedman HL. The health of adolescents: beliefs and behaviour. Soc Sci Med. 1989;29(3):309-315.

15. Tan JK, Vasey K, Fung KY. Beliefs and perceptions of patients with acne. J Am Acad Dermatol. 2001;44(3):439-445.

16. Magin P, Pond D, Smith W, Watson A. A systematic review of the evidence for 'myths and misconceptions' in acne management: diet, face-washing and sunlight. Fam Pract. 2005;22(1):62-70.

17. Plewig G, Fulton JE, Kligman AM. Pomade acne. Arch Dermatol. 1970;101(5):580-584.

18. Jugeau S, Tenaud I, Knol AC, et al. Induction of toll-like receptors by Propionibacterium acnes. Br J Dermatol. 2005;153(6): 1105-1113.

19. Kim J. Review of the innate immune response in acne vulgaris: activation of Toll-like receptor 2 in acne triggers inflammatory cytokine responses. Dermatology. 2005;211(3):193-198.

20. Danby FW. Acne Causes and Practical Management. Hoboken, NJ: Wiley Blackwell; 2015.

21. Parker LN. Adrenarche. Endocrinol Metab Clin North Am. 1991;20(1): 71-83.

22. Martinez G, Copen CE, Abma JC. Teenagers in the United States: sexual activity, contraceptive use, and childbearing, 2006-2010 national survey of family growth. Vital Health Stat. 2011;23(31):1-35.

23. Calman KC, Muir AV, Milne JA, Young H. Survey of the distribution of steroid dehydrogenases in sebaceous glands of human skin. $\mathrm{Br} \mathrm{J}$ Dermatol. 1970;82(6):567-571.

24. Melnik BC. The role of transcription factor FoxO1 in the pathogenesis of acne vulgaris and the mode of isotretinoin action. G Ital Dermatol Venereol. 2010;145(5):559-571.

25. Melnik BC, Zouboulis CC. Potential role of FoxO1 and mTORC1 in the pathogenesis of Western diet-induced acne. Exp Dermatol. 2013;22(5):311-315.

26. Caprio S, Plewe G, Diamond MP, et al. Increased insulin secretion in puberty: a compensatory response to reductions in insulin sensitivity. J Pediatr. 1989;114(6):963-967.

27. Melnik BC. Is nuclear deficiency of FoxO1 due to increased growth factor/PI3K/Akt-signalling in acne vulgaris reversed by isotretinoin treatment? Br J Dermatol. 2010;162:1398-1400.

28. 8/1 M. Parents and Teachers: Teen Growth and Development, Years 15 to 17; 2015. Available from: http://www.pamf.org/parenting-teens/ health/growth-development/growth.html. Accessed May 29, 2015.

29. Smith CP, Dunger DB, Williams AJ, et al. Relationship between insulin, insulin-like growth factor I, and dehydroepiandrosterone sulfate concentrations during childhood, puberty, and adult life. J Clin Endocrinol Metab. 1989;68(5):932-937.

30. Plant TM. Neuroendocrine control of the onset of puberty. Front Neuroendocrinol. 2015;38:73-88.

31. Stathakis V, Kilkenny M, Marks R. Descriptive epidemiology of acne vulgaris in the community. Australas J Dermatol. 1997;38(3): 115-123.

32. French SA, Story M, Neumark-Sztainer D, Fulkerson JA, Hannan P. Fast food restaurant use among adolescents: associations with nutrient intake, food choices and behavioral and psychosocial variables. Int $J$ Obes Relat Metab Disord. 2001;25(12):1823-1833.

33. Drewnowski A, Popkin BM. The nutrition transition: new trends in the global diet. Nutr Rev. 1997;55(2):31-43.

34. Kwon HH, Yoon JY, Hong JS, Jung JY, Park MS, Suh DH. Clinical and histological effect of a low glycaemic load diet in treatment of acne vulgaris in Korean patients: a randomized, controlled trial. Acta Derm Venereol. 2012;92(3):241-246.

35. Ismail NH, Manaf ZA, Azizan NZ. High glycemic load diet, milk and ice cream consumption are related to acne vulgaris in Malaysian young adults: a case control study. BMC Dermatol. 2012;12:13.

36. Zouboulis CC, Jourdan E, Picardo M. Acne is an inflammatory disease and alterations of sebum composition initiate acne lesions. J Eur Acad Dermatol Venereol. 2014;28(5):527-532.

37. Melnik B. Dietary intervention in acne: Attenuation of increased mTORC1 signaling promoted by Western diet. Dermatoendocrinol. 2012;4(1):20-32. 
38. Smith RN, Mann NJ, Braue A, Makelainen H, Varigos GA. The effect of a high-protein, low glycemic-load diet versus a conventional, high glycemic-load diet on biochemical parameters associated with acne vulgaris: a randomized, investigator-masked, controlled trial. J Am Acad Dermatol. 2007;57(2):247-256.

39. Burris J, Rietkerk W, Woolf K. Acne: the role of medical nutrition therapy. J Acad Nutr Diet. 2013;113(3):416-430.

40. Robinson HM. The acne problem. South Med J. 1949;42(12): 1050-1060, illust.

41. Adebamowo CA, Spiegelman D, Danby FW, Frazier AL, Willett WC, Holmes MD. High school dietary dairy intake and teenage acne. $J$ Am Acad Dermatol. 2005;52(2):207-214.

42. Adebamowo CA, Spiegelman D, Berkey CS, et al. Milk consumption and acne in adolescent girls. Dermatol Online J. 2006;12(4):1.

43. Adebamowo CA, Spiegelman D, Berkey CS, et al. Milk consumption and acne in teenaged boys. J Am Acad Dermatol. 2008;58(5):787-793.

44. Koldovsky O. Hormones in milk. Life Sci. 1980;26(22):1833-1836.

45. Yeung A, Sheehan J. Hormone Concentrations in Milk and Milk Products [Letter from FDA Center for Food Safety and Applied Nutrition]. Washington, DC: US Food and Drug Administration; 2012.

46. Millward DJ, Layman DK, Tome D, Schaafsma G. Protein quality assessment: impact of expanding understanding of protein and amino acid needs for optimal health. Am J Clin Nutr. 2008;87(5):1576s-1581s.

47. Delnevo CD, Bover Manderski MT, Giovino GA. Youth tobacco use and electronic cigarettes. JAMA Pediatr. 2014;168:775-776.

48. Administration SAaMHS. Results from the 2010 National Survey on Drug Use and Health: Mental Health Findings. Rockville, MD: Substance Abuse and Mental Health Services Administration; 2012.

49. Dutra LM, Glantz SA. Electronic cigarettes and conventional cigarette use among US adolescents: a cross-sectional study. JAMA Pediatr. 2014;168(7):610-617.

50. Carroll Chapman SL, Wu LT. E-cigarette prevalence and correlates of use among adolescents versus adults: a review and comparison. J Psychiatr Res. 2014;54:43-54.

51. Klaz I, Kochba I, Shohat T, Zarka S, Brenner S. Severe acne vulgaris and tobacco smoking in young men. J Invest Dermatol. 2006;126(8): 1749-1752.

52. Schafer T, Nienhaus A, Vieluf D, Berger J, Ring J. Epidemiology of acne in the general population: the risk of smoking. $\mathrm{Br} J$ Dermatol. 2001;145(1):100-104.

53. Capitanio B, Sinagra JL, Ottaviani M, Bordignon V,Amantea A, Picardo M. Acne and smoking. Dermatoendocrinol. 2009;1(3):129-135.

54. Pelle E, Miranda EP, Fthenakis C, Mammone T, Marenus K, Maes D. Cigarette smoke-induced lipid peroxidation in human skin and its inhibition by topically applied antioxidants. Skin Pharmacol Appl Skin Physiol. 2002;15(1):63-68.

55. Halvorsen JA, Stern RS, Dalgard F, Thoresen M, Bjertness E, Lien L. Suicidal ideation, mental health problems, and social impairment are increased in adolescents with acne: a population-based study. J Invest Dermatol. 2011;131(2):363-370.

56. Silverberg JI, Silverberg NB. Epidemiology and extracutaneous comorbidities of severe acne in adolescence: a US population-based study. Br J Dermatol. 2014;170(5):1136-1142.

57. Smithard A, Glazebrook C, Williams HC. Acne prevalence, knowledge about acne and psychological morbidity in mid-adolescence: a community-based study. Br J Dermatol. 2001;145(2):274-279.

58. Spencer EH, Ferdowsian HR, Barnard ND. Diet and acne: a review of the evidence. Int J Dermatol. 2009;48(4):339-347.

59. Wen L, Jiang G, Zhang X, Lai R, Wen X. Relationship between acne and psychological burden evaluated by ASLEC and HADS surveys in high school and college students from central China. Cell Biochem Biophys. 2015;71(2):1083-1088.

60. Bettoli V, Zauli S. The epidemiology and comorbidities of severe acne in children aged 0-17 years. Br J Dermatol. 2014;170(5):1013-1014.

61. Bowe WP, Hoffstad O, Margolis DJ. Upper respiratory tract infection in household contacts of acne patients. Dermatology. 2007;215(3): 213-218.
62. Levy RM, Huang EY, Roling D, Leyden JJ, Margolis DJ. Effect of antibiotics on the oropharyngeal flora in patients with acne. Arch Dermatol. 2003;139(4):467-471.

63. Margolis DJ, Bowe WP, Hoffstad O, Berlin JA. Antibiotic treatment of acne may be associated with upper respiratory tract infections. Arch Dermatol. 2005;141(9):1132-1136.

64. Bataille V, Snieder H, MacGregor AJ, Sasieni P, Spector TD. The influence of genetics and environmental factors in the pathogenesis of acne: a twin study of acne in women. J Invest Dermatol. 2002;119(6): $1317-1322$.

65. Friedman GD. Twin studies of disease heritability based on medical records: application to acne vulgaris. Acta Genet Med Gemellol (Roma). 1984;33(3):487-495.

66. Schackert K, Scholz S, Steinbauer-Rosenthal I, Albert ED, Wank R, Plewig G. Letter: HL-A antigens in acne conglobata: a negative study. Arch Dermatol. 1974;110(3):468.

67. Wong SS, Pritchard MH, Holt PJ. Familial acne fulminans. Clin Exp Dermatol. 1992;17(5):351-353.

68. Ando I, Kukita A, Soma G, Hino H. A large number of tandem repeats in the polymorphic epithelial mucin gene is associated with severe acne. J Dermatol. 1998;25(3):150-152.

69. Klinger B, Anin S, Silbergeld A, Eshet R, Laron Z. Development of hyperandrogenism during treatment with insulin-like growth factor-I (IGF-I) in female patients with Laron syndrome. Clin Endocrinol (Oxf). 1998;48(1):81-87.

70. Melnik BC, John SM, Plewig G. Acne: risk indicator for increased body mass index and insulin resistance. Acta Derm Venereol. 2013;93(6): 644-649.

71. Zouboulis CC. Acne as a chronic systemic disease. Clin Dermatol. 2014;32(3):389-396.

72. Simonart T. Newer approaches to the treatment of acne vulgaris. Am J Clin Dermatol. 2012;13(6):357-364.

73. Dreno B. Topical antibacterial therapy for acne vulgaris. Drugs. 2004;64(21):2389-2397.

74. Gollnick HP. From new findings in acne pathogenesis to new approaches in treatment. J Eur Acad Dermatol Venereol. 2015;29 (Suppl 5):1-7.

75. Webster G. Combination azelaic acid therapy for acne vulgaris. $J A m$ Acad Dermatol. 2000;43(2 pt 3):S47-S50.

76. Strauss JS, Krowchuk DP, Leyden JJ, et al; American Academy of Dermatology/American Academy of Dermatology Association. Guidelines of care for acne vulgaris management. JAm Acad Dermatol. 2007;56(4):651-663.

77. Dawson AL, Dellavalle RP. Acne vulgaris. BMJ. 2013;346:f2634.

78. Gollnick H, Cunliffe W, Berson D, et al. Management of acne: a report from a global alliance to improve outcomes in acne. $J$ Am Acad Dermatol. 2003;49(1 Suppl):S1-S37.

79. Simonart T, Dramaix M, De Maertelaer V. Efficacy of tetracyclines in the treatment of acne vulgaris: a review. Br J Dermatol. 2008;158(2): 208-216.

80. Thiboutot D, Gollnick H, Bettoli V, et al; Global Alliance to Improve Outcomes in Acne. New insights into the management of acne: an update from the Global Alliance to Improve Outcomes in Acne group. J Am Acad Dermatol. 2009;60(5 Suppl):S1-S50.

81. Harper JC. An update on the pathogenesis and management of acne vulgaris. J Am Acad Dermatol. 2004;51(1 Supp1):S36-S38.

82. Nast A, Dreno B, Bettoli V, et al. European evidence-based (S3) guidelines for the treatment of acne. J Eur Acad Dermatol Venereol. 2012;26(Suppl 1):1-29.

83. Chivot M. Retinoid therapy for acne. A comparative review. Am J Clin Dermatol. 2005;6(1):13-19.

84. DiGiovanna JJ. Systemic retinoid therapy. Dermatol Clin. 2001;19(1): 161-167.

85. Chivot M. Retinoid therapy for acne. A comparative review. Am J Clin Dermatol. 2005;6(1):13-19.

86. DiGiovanna JJ. Systemic retinoid therapy. Dermatol Clin. 2001;19(1): 161-167. 
87. Panzer C, Wise S, Fantini G, et al. Impact of oral contraceptives on sex hormone-binding globulin and androgen levels: a retrospective study in women with sexual dysfunction. $J$ Sex Med. 2006;3(1):104-113.

88. Prevost N, English JC. Isotretinoin: update on controversial issues. J Pediatr Adolesc Gynecol. 2013;26(5):290-293.

89. Haider A, Shaw JC. Treatment of acne vulgaris. JAMA. 2004;292(6): 726-735.

90. Newman MD, Bowe WP, Heughebaert C, Shalita AR. Therapeutic considerations for severe nodular acne. Am J Clin Dermatol. 2011;12(1):7-14.

91. Kohler C, Tschumi K, Bodmer C, Schneiter M, Birkhaeuser M. Effect of finasteride $5 \mathrm{mg}$ (Proscar) on acne and alopecia in female patients with normal serum levels of free testosterone. Gynecol Endocrinol. 2007;23(3):142-145.

92. Panzer C, Wise S, Fantini G, et al. Impact of oral contraceptives on sex hormone-binding globulin and androgen levels: a retrospective study in women with sexual dysfunction. J Sex Med. 2006;3(1): 104-113.

93. Thorneycroft H, Gollnick H, Schellschmidt I. Superiority of a combined contraceptive containing drospirenone to a triphasic preparation containing norgestimate in acne treatment. Cutis. 2004;74(2): $123-130$.
94. Farmer RD, Lawrenson RA, Thompson CR, Kennedy JG, Hambleton IR Population-based study of risk of venous thromboembolism associated with various oral contraceptives. Lancet. 1997;349(9045):83-88.

95. Phillips A, Hahn DW, McGuire JL. Preclinical evaluation of norgestimate, a progestin with minimal androgenic activity. Am J Obstet Gynecol. 1992;167(4 pt 2):1191-1196.

96. Corson SL. Efficacy and clinical profile of a new oral contraceptive containing norgestimate. US clinical trials. Acta Obstet Gynecol Scand Suppl. 1990;152:25-31.

97. Collier R. Scrutiny of Diane-35 due to potential dangers of off-label prescribing. CMAJ. 2013;185:E217-E218.

98. Brahm J, Brahm M, Segovia R, et al. Acute and fulminant hepatitis induced by flutamide: case series report and review of the literature. Ann Hepatol. 2011;10(1):93-98.

99. Cilotti A, Danza G, Serio M. Clinical application of 5alpha-reductase inhibitors. J Endocrinol Invest. 2001;24(3):199-203.

100. Biggar RJ, Andersen EW, Wohlfahrt J, Melbye M. Spironolactone use and the risk of breast and gynecologic cancers. Cancer Epidemiol. 2013;37(6):870-875.

101. Joseph MA, Jayaseelan E, Ganapathi B, Stephen J. Hidradenitis suppurativa treated with finasteride. $J$ Dermatolog Treat. 2005;16(2):75-78.
Adolescent Health, Medicine and Therapeutics

\section{Publish your work in this journal}

Adolescent Health, Medicine and Therapeutics is an international, peer-reviewed, open access journal focusing on health, pathology, and treatment issues specific to the adolescent age group. All aspects of health maintenance, preventative measures and disease treatmen interventions are addressed within the journal and practitioners from

\section{Dovepress}

all disciplines are invited to submit their work as well as healthcare researchers and patient support groups.. The manuscript management system is completely online and includes a very quick and fair peerreview system. Visit http://www.dovepress.com/testimonials.php to read real quotes from published authors. 